\title{
Development of a Graphical User Interface to Visualize Surface Observations
}

by

R. L. Buckley

Westinghouse Savannah River Company

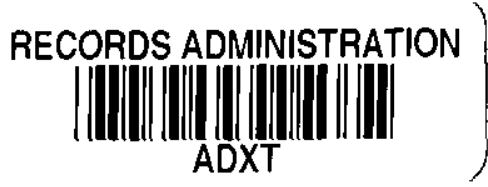

Savannah River Site

Aiken, South Carolina 29808

This paper was prepared in connection with work done under the above contract number with the U. S. Department of Energy. By acceptance of this paper, the publisher and/or recipient acknowledges the U. S. Government's right to retain a nonexclusive, royalty-free license in and to any copyright covering this paper, along with the right to reproduce and to authorize others to reproduce all or part of the copyrighted paper. 


\section{DEVELOPMENT OF A GRAPHICAL USER INTERFACE TO VISUALIZE SURFACE OBSERVATIONS (U)}

Robert L. Buckley

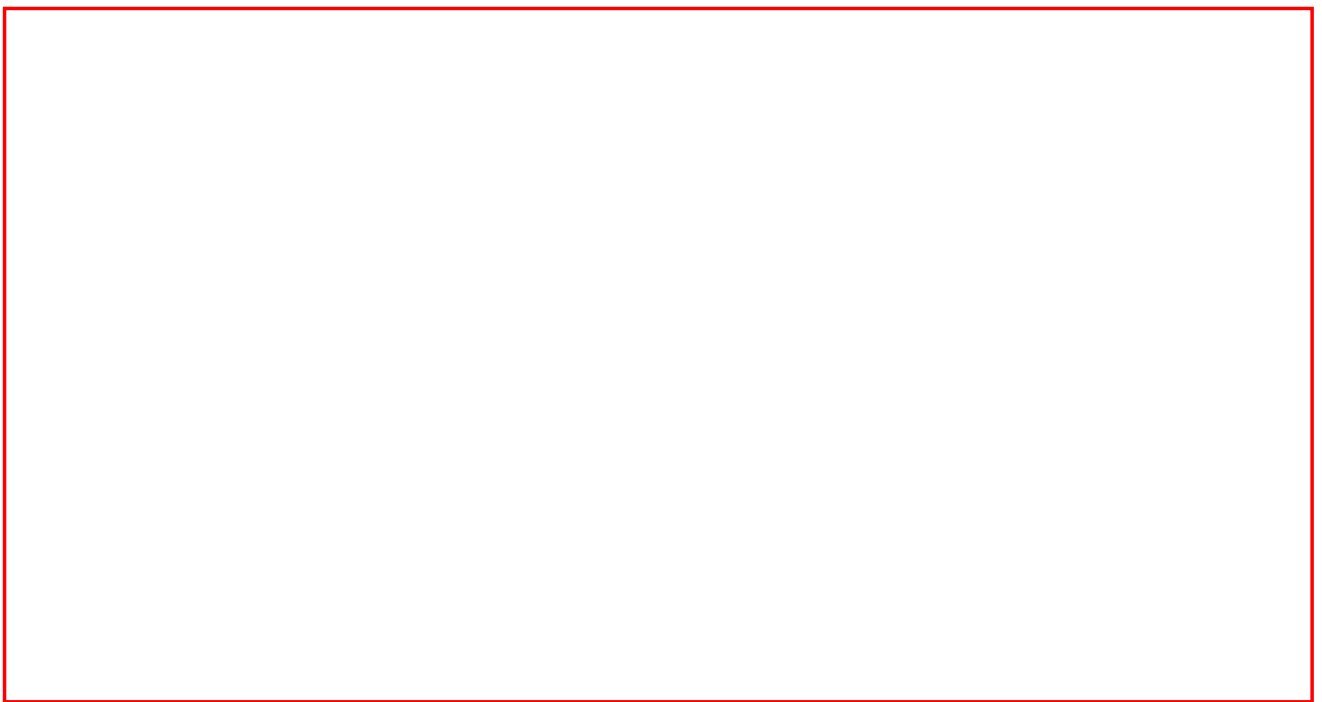

June 1998

Westinghouse Savannah River Company Savannah River Site

Aiken, SC 29808

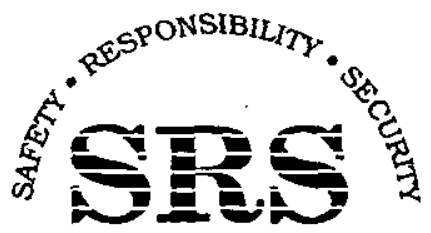

SAVANNAH RIVER SITE

PREPARED FOR THE U.S. DEPARTMENT OF ENERGY UNDER CONTRACT NO. DE-AC09-96SR18500 


\section{DISCLAIMER}

This report was prepared as an account of work sponsored by an agency of the United States Government.' Neither the United States Government nor any agency thereof, nor any of their - employees, makes any warranty, express or implied, or assumes any legal liability or responsibility for the accuracy, completeness, or usefulness of any information, apparatus, product, or process disclosed, or represents that its use would not infringe privately owned rights. Reference: herein to any specific commercial product, process, or service by trade name, trademark, manufacturer, or otherwise does not necessarily constitute or imply its endorsement, recommendation, or favoring by the United States Government or any agency ihereof. The views and opinions of authors expressed herein do not necessarily state or reflect those of the United States Govemment or any agency thereof.

This report has been reproduced directly from the best available copy.

Available to DOE and DOE contractors from the Office of Scientific and Technical Information, P.O. Box 62, Oak Ridge, TN 37831; prices available from (615) 576-8401.

$\therefore$ Available to the public from the National Technical Information Service, U.S. Department of Comînerce, 5285 Port Royal Road, Springfield, VA 22161. 


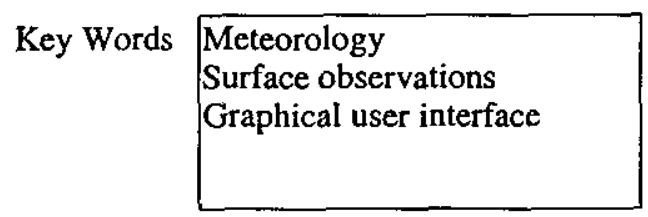

Retention: Lifetime

\section{DEVELOPMENT OF A GRAPHICAL USER INTERFACE TO VISUALIZE SURFACE OBSERVATIONS (U)}

Robert L. Buckley

Issued: June 1998 


\section{ABSTRACT}

Thousands of worldwide observing stations provide meteorological information near the earth's surface as often as once each hour. This surface data may be plotted on geographical maps to provide the meteorologist useful information regarding weather patterns for a region of interest. This report describes the components and applications of a graphical user interface which have been developed to visualize surface observations at any global location and time of interest. 


\section{TABLE OF CONTENTS}

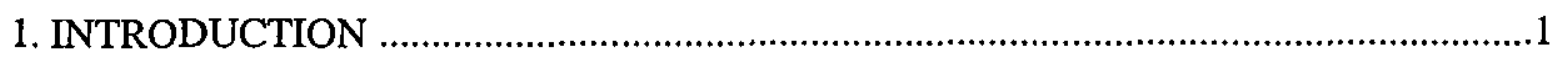

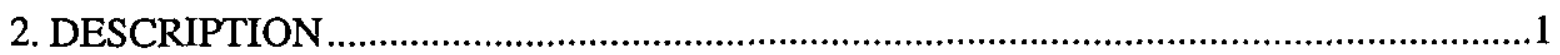

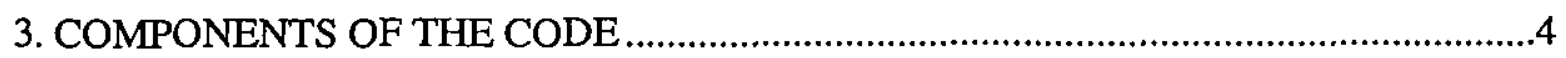

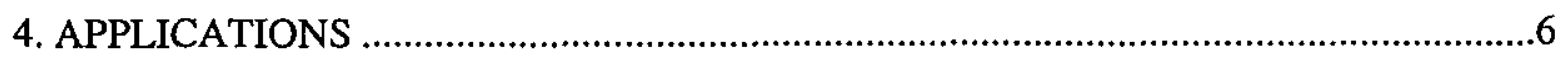

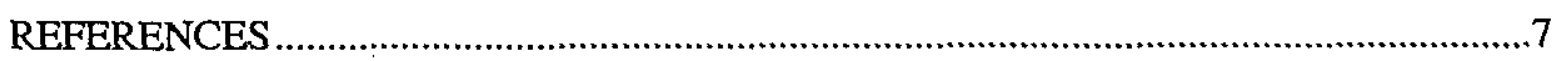

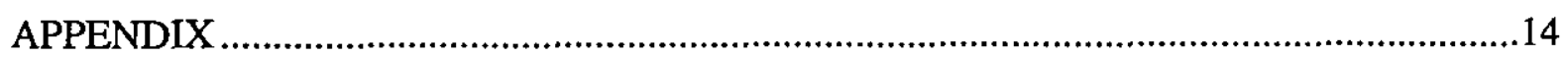




\section{LIST OF FIGURES}

Figure 1: Flow diagram of the surface observation graphical user interface

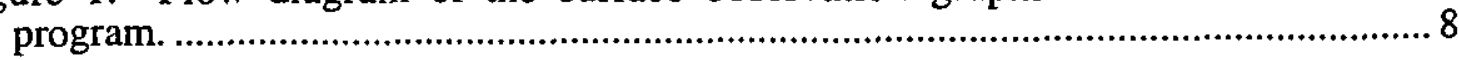

Figure 2: Determination of the area ('box') in which surface data is selected based on user input of center latitude $\left(\mathrm{C}_{\mathrm{LAT}}\right)$, center longitude $\left(\mathrm{C}_{\mathrm{LON}}\right)$, and range $(R)$.

Figure 3: Available surface station locations across the mainland United States. (a) METAR, (b) WMO synoptic bulletin. The number of stations in the domain is indicated in the lower left corner of each figure.

Figure 4: Symbolic station model with a key explaining the meteorological quantity represented by the symbols.

Figure 5: Screen image of the graphical user interface for a user-selected time (17 April 1998, 06Z) and location $\left(\mathrm{C}_{\mathrm{LAT}}=65^{\circ} \mathrm{N}, \mathrm{C}_{\mathrm{LON}}=15^{\circ} \mathrm{E}, R=1000 \mathrm{~km}\right)$ in northern Europe.

Figure 6: Screen image of an individual station report taken from Fig. 5. This station is located in Ostersund, Sweden. 


\title{
DEVELOPMENT OF A GRAPHICAL USER INTERFACE TO VISUALIZE SURFACE OBSERVATIONS (U)
}

\author{
Robert L. Buckley \\ Westinghouse Savannah River Company \\ Savannah River Site \\ Aiken, SC 29808
}

\section{INTRODUCTION}

The Atmospheric Technologies Group (ATG) of the Savannah River Technology Center (SRTC) collects and archives data from Weather Services International (WSI) on a daily basis. Both surface and upper-air observations are collected by governmental agencies around the world at varying time intervals $(1,3$, or 12 hours). It is important to be able to present this information in a concise, efficient manner. This report focuses on surface observations from stationary locations.

Two types of surface observations are currently archived by ATG. Synoptic bulletins are received worldwide at 3-hr intervals (up to a total of 9000 ), while METAR surface observations (maximum of -3800 ) are acquired on an hourly basis. The METAR coverage is more dense, but is restricted mainly to western hemisphere locations. Both sets of data are contained in files named according to the time at which the observations are valid. The surface bulletins are written in alphanumeric coded messages according to formats specified by the World Meteorological Organization (WMO-No. 306, 1995), while the METAR data formats are specified by the U. S. Department of Commerce (METAR, 1996).

Procedures have been written in the Interactive Data Language (IDL, version 4.0.1, IDL User's Guide, 1995) to first decode relevant meteorological information (i.e. barometric pressure, temperature, dewpoint, wind speed, etc.) from these files into array form. A graphical user interface (GUI) for each type of surface observation has been built to display this information overlayed on a geographical map of the desired worldwide location. The format and structure of the interface is similar to a previously developed GUI to display upper-air meteorological data (Buckley, 1997). The interfaces currently run on an IBM RISC/6000 workstation using a Unix operating system and a WindowsNT PC platform.

Besides providing insight into weather patterns for a particular region, the surface data obtained from the decoding procedures can be used as input into numerical mesoscale models and atmospheric transport codes. The purpose of this report is to describe the general interface structure and its components.

\section{DESCRIPTION}

The use of a menu-driven GUI allows the user to more easily input and display surface observations than a code requiring specific keyboard inputs. The GUI for each type of surface observation is similar, and the following descriptions apply to both, except where differences are noted. A series of 'widget' procedures within IDL is used to create the GUI. This involves creating a 'base' widget upon which other widgets of varying 
complexity and design are used to carry out a function and/or display an image. The basic code structure is in the form of a series of procedures and functions. Note that procedures within the IDL programming language are equivalent to Fortran subroutines. A flow diagram of the GUI is illustrated in Fig. 1.

The user is first prompted to select a time and central location from which to examine the meteorological data. Surface data is then gathered in a user-specified region about this central location. The center location is entered as a latitude and longitude. The center latitude values must be between $-90^{\circ}$ and $+90^{\circ}$ where negative quantities imply a center point within the southern hemisphere and positive quantities within the northern hemisphere. Likewise, the center longitude must be between $-180^{\circ}$ and $+180^{\circ}$ with western hemisphere locations denoted by negative numbers and eastern hemisphere places given by positive numbers.

For the WMO synoptic bulletins, data is archived from WSI at $00,03,06,09,12,15,18$, and 21 Greenwich Mean Time (GMT, often reported as Z, or Zulu, time), while the surface METAR data is available every hour. An $\mathrm{DL}$ procedure (pickfile.pro) is utilized which prompts the user to enter a selection from a list of files in a given directory containing the WSI surface data. The format of the filenames is 'mmddyyyy_hhZ' where ' $m$ ' is the month in integer form $(01,02, \ldots, 12)$, 'dd' is the day, 'yyyy' is the year, and ' $h$ ' is the hour, corresponding to GMT or Z. Separate directories exist for each type of surface data.

The sampling range $(\mathrm{km})$ is used to determine maximum and minimum latitudes and longitudes from which to sample possible stations. The range refers to the total distance from west-to-east and from north-to-south running through the center latitude and longitude. Thus, if a range of $100 \mathrm{~km}$ is selected, points up to $50 \mathrm{~km}$ east and $50 \mathrm{~km}$ west would be included. Note that the 'box' from which stations are selected is actually one of constant latitude along the top and bottom, and one of constant longitude along the right and left sides of the domain. This is illustrated in Fig. 2 for a center point located within the northern hemisphere. Note that the domain of interest is not allowed to extend over either of the poles, but is instead assumed to stop at the pole. As illustrated in Fig. 3 , network coverage within the mainland United States is three times greater using the METAR dataset. In either case, selection of a large geographical range $(>1500 \mathrm{~km})$ could result in extremely 'busy' images.

After the time and location is satisfactorily entered, the data is found and decoded for the relevant stations and a map is drawn showing the countries (continents) in which surface observations are desired. A datafile containing the latitude, longitude, and elevation associated with a unique 5-digit integer station identification (station ID) is accessed for the WMO synoptic reports (e.g. 72219 for Atlanta, GA). METAR station data is delineated by a 4-character station ID (e.g. KATL for Atlanta, GA). For each station within the selected domain, a surface weather report is drawn. A symbolic weather report with possible available information is shown in Fig. 4 (see, for example, Lutgens and Tarbuck, 1989). Winds are shown in the form of barbs (ff, dd), illustrating the direction from which wind is blowing, with flags and feathers denoting wind speed $\left(\mathrm{m} \mathrm{s}^{-1}\right)$. The total amount of sky coverage by clouds is denoted by the central circle (N), which is filled if conditions are overcast, and hollow if conditions are clear.

Because surface network coverage may be dense, and selection of a large region may lead to images which are diffucult to discern, only a limited amount of information from each station report is plotted on the large geographical map in the GUI. In addition to sky coverage and winds, the temperature $\left({ }^{\circ} \mathrm{C}\right.$, "TT" from Fig. 4$)$, dewpoint temperature $\left({ }^{\circ} \mathrm{C}\right.$, 
" $\mathrm{T}_{\mathrm{d}} \mathrm{T}_{\mathrm{d}}$ "), and barometric pressure (mb, "PPP") are also shown for each surface observation on the map image created in the GUI. Other information displayed on the surface GUI map includes the domain range, center location, the time at which observations are valid, the number of stations contained within the domain, and a legend explaining the meaning of the various parts of each station report.

The interface also allows the user to view additional information for a particular station (by depressing the "VIEW Station" widget button). Selection of an individual station then occurs when the cursor is placed on the sky-coverage circle central to the observation and the mouse button is depressed. When this action is performed, an additional smaller image is displayed within the interface, showing the station ID, latitude $\left({ }^{\circ} \mathrm{N}\right)$, longitude $\left({ }^{\circ} \mathrm{E}\right)$, and elevation (meters above sea level). Also indicated (if available in the report) is the visibility ( $\mathrm{km}$, "VV"), the height of the lowest cloud base (meters, " $h ")$, the pressure tendency (mb change in past 3 hours, "pp", and upward or downward tendency, "a"), the amount of precipitation (mm, "RR"), and the time over which the precipitation was measured $\left(\mathrm{hr}\right.$, " $\left.\mathrm{R}_{\mathrm{t}}{ }^{\prime}\right)$.

The user has the option to create an output image of the map for other applications. In addition, when the user exits the GUI, or selects a different time, the observational data for the previous time is saved into a text file which may be used as input for reports or other modeling applications. Note that if a different location is selected for the same time period, results in the text file are overwritten, since the name of the output text file is determined by the name of the input file (which are determined by the unique time of the observation).

Figure 5 is a screen-dump image of the GUI showing the various components. The time and location is input in the upper left portion. When the program is executed, this is the only part of the GUI which is visible to the user. After successful data entry, a map is produced to the right, with depictions of station locations and other pertinent information. This particular plot is centered on Sweden $\left(65^{\circ} \mathrm{N}, 15^{\circ} \mathrm{E}\right)$ on 17 April 1998 and contains 20 stations (synoptic surface observation). An area containing comments and instructions to the user is shown on the middle-left side of the GUI. For this example, winds are generally from the east, with temperatures ranging from -8 to $+6^{\circ} \mathrm{C}$, with cooler temperatures further north. Dewpoint temperatures, an indicator of moisture in the air, reveal dryer conditions to the north, and moist conditions (i.e. relative humidites of $100 \%$ ) in the southermost portion of the domain in Sweden. Most of the region appears to be overcast, with the exception of the northeastern corner.

An individual station has been selected as well and is shown in the lower left portion of the GUI. This image is also shown in Fig. 6. For this particular time (06Z, 17 April 1998) and location (Ostersund, Sweden), winds are from the east-northeast between 2.5 and $5.0 \mathrm{~m} \mathrm{~s}^{-1}$. The barometric pressure is $958 \mathrm{mb}$ and has dropped $0.4 \mathrm{mbar}$ over the previous 3 hours, while a trace of precipitation has fallen over the past 12 hours While sky coverage indicates totally overcast conditions, the lowest cloud base is estimated to be 300 to $600 \mathrm{~m}$ above ground level. The temperature is $0^{\circ} \mathrm{C}$ and the dewpoint temperature is $-2^{\circ} \mathrm{C}$, while the visibility is $10 \mathrm{~km}$. The text file containing information for all of the stations within the domain for this example is shown in the Appendix.

To exit the GUI completely, the 'EXIT' widget button in the upper left portion must be depressed. 


\section{COMPONENTS OF THE CODE}

The various procedures and functions used or developed for this application are briefly described in this section.

drawing.pro: This procedure uses the user-selected input location and range to draw the mapping domain. The IDL mapping procedure 'map_set.pro' is then called to draw the country (or state) and continent outlines of the region. Symbolic surface station reports are placed on the map at their geographical location. Printed along the top of the image is the domain size, center latitude/longitude coordinates, the valid time of observation, as well as the number of stations within the selected area. A legend is also shown denoting the different colors used for temperature, dewpoint, and pressure as reported for each station, along with the denominations used for the wind barb flags and feathers.

driver.pro: This is the main driver for the entire interface. It creates the base ('parent') widget and all other ('children') widgets under it. In Fig. 5, this 'parent'-widget encompasses the entire image and is labeled 'SURFACE OBSERVATIONS'. An information structure is created in this module and is passed among the widgets and procedures. Values for the various parameters needed within the different procedures (e.g. location and time) are stored in this structure, similar to 'common' blocks used in Fortran. An 'event handler' is used in the widget program to perform tasks based on user input (i.e. what action must be taken if a particular widget button is selected). All major decisions are controlled within this event handler. This includes error checking of input data, the existence of stations within the chosen area, the existence of data for the given station ID and time, as well as creating hardcopy output.

function map_get: This function is called by a widget drawing procedure to plot the map boundaries and surface observations falling within the 'box.' Within this function a procedure is called ('drawing.pro') which does the mapping. The boundaries of the 'box' are plotted in the function (this is essentially the right side of Fig. 5). In addition, the position (in device, or pixel, coordinates) of each station on the map is saved for later use in individual station plots. All of the meteorological data obtained from the decoding of the surface observations records is also saved into arrays for later plotting purposes. The actual surface station plots are created using 'plot_station_all.pro'.

function station_indiv_get: This function is called by a widget drawing procedure to plot a specific user-selected station. It is activated when the user selects the widget button labeled "VIEW Station." The pixel corresponding to the station center is already known ('function map_get'). Thus, if the user activates "VIEW Station," then selects a pixel value (using the mouse button and cursor) within the circle specifying sky coverage for an individual station, then that data is retrieved from an array and plotted on a separate draw widget on the left-side of the base widget (see Figs. 5 and 6). The surface station plot is created using 'plot_station_indiv.pro'.

latlon_get.pro: This procedure determines the latitude/longitude bounds based on user input. If the range is chosen such that the domain would cross over either the North or South pole, then the range is reduced to stop at the poles. Therefore, the user is cautioned not to select a latitude near the poles, as the size of the domain is severely reduced and very few stations exist at these locations. In addition, the possible problems at longitude crossover from $+180^{\circ}$ to $-180^{\circ}$ must be handled here. With a large number of stations, the map tends to becomes cluttered reducing its 
effectiveness in imparting information to the user. This is especially true if METAR data is accessed over a large region of the United States (Fig. 3a).

plot_station_all.pro: Each station in the domain of interest is plotted on the draw widget image. Uniform size for all stations is ensured by converting the geographical location of the station to device (pixel) coordinates. The information plotted on the large map is limited to: wind barbs showing wind direction and speed $\left(\mathrm{m} \mathrm{s}^{-1}\right)$, a circle in the center which denotes sky coverage, temperature $\left({ }^{\circ} \mathrm{C}\right)$ in to the upper left of center, dewpoint temperature $\left({ }^{\circ} \mathrm{C}\right)$ in green to the lower left, and barometric pressure $(\mathrm{mb})$ in blue to the upper right. If temperature, dewpoint, or pressure is missing, the letter ' $M$ ' is placed on the station drawing. For the wind barb, full flags represent speeds equal to $25 \mathrm{~m} \mathrm{~s}^{-1}$, while long feathers and short feathers represent speeds of 5 and $2.5 \mathrm{~m} \mathrm{~s}^{-1}$. Sky coverage is as follows:

Hollow circle: clear skies, fractional sky coverage:

Hollow circle with single vertical line through center:

One-quarter filled circle:

One-quarter filled and vertical line to bottom of circle:

One-half filled circle:

One-half filled circle and horizontal line to left of circle:

Three-quarters filled circle:

Filled circle except vertical white line through center:

Filled circle: completely overcast

Hollow circle with $\mathrm{X}$ in middle:

Hollow circle with $\mathrm{M}$ in middle:

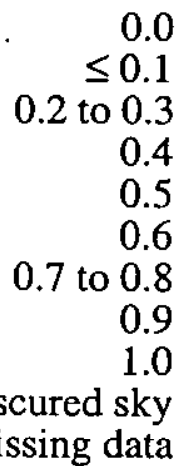

missing data

plot_station_indiv.pro: An individual user-selected surface station is plotted on a draw widget image. Conversion of the geographical location of the station to device (pixel) coordinates is performed here as well. In addition to the data plotted in 'plot_station_all.pro', the following is also included: station ID (5-digit for WMO synoptic surface, 4-characters for METAR), station location and elevation (m above sea level, ASL), visibility ( $\mathrm{km}$ ) in pink to the left of center, lowest cloud height base ( $m$ above ground level, AGL) in light blue at bottom level below center, precipitation amount ( $\mathrm{mm}$ ) in tan below and right of center, duration of precipitation measurement $(\mathrm{hr})$ in orange in the lower right corner, and pressure change and tendency $( \pm \mathrm{mb})$ in dark green to the right of center (see Fig. 6 for example).

read_surf.pro: Decoding of the datastrings occurs in this procedure. Major differences between the METAR and WMO synoptic surface bulletin GUI's originate here. The general procedure in both instances is to first read in the raw data (line by line), eliminate carriage returns and extra spaces, and create strings representing a given data record. In the case of the WMO surface bulletins, the distinctive feature of each record is its 5-digit station ID, while for the METAR data, it is a 4-character alphabetical string at the beginning of each record. Records which contain no information are then eliminated, as well as any duplicate records contained within the file. Finally, only those stations within the user specified region are kept. Each remaining string is then decoded using string-manipulation routines within IDL and meteorological information such as temperature or dewpoint is extracted. Results are then placed into a text file which may be used elsewhere (see the Appendix for an example). 


\section{APPLICATIONS}

The visual information depicted in these surface plots is useful in the determination of frontal location and are often used by meteorologists. However, such data is usually not archived and plots from readily available sources such as WSI are only valid at the current time. If results are archived, they are usually in the form of plots for a specified station or geographic region. The interface as written here is unique in that it accesses data at any time and global location. Perhaps of more importance is the application of this meteorological data in other models. Once the data is decoded, it can be used as input to numerical mesoscale models such as the Regional Atmospheric Modeling System (RAMS, Pielke et al. 1992). Realistic surface fields can be generated using standard interpolation routines such as the Barnes objective analysis technique (Barnes 1964), or in combination with upper-air soundings and/or large-scale pressure fields to initialize wind, temperature, and moisture fields in multiple-dimensions. Results from the numerical models may also be validated by comparison with the observed data. Surface observations are important in this application due to a more dense network coverage when compared with upper-air radiosondes.

Another obvious application of the data is in the direct input of wind fields for dispersion modeling. Dispersion models have applications in air-quality and environmental assessments, emergency response, and non-proliferation. Often, these models require only two-dimensional winds as input to reduce computational time, and the existence of readily available surface observations necessarily leads to more accurate plume predictions. 


\section{REFERENCES}

Buckley, R. L., 1997: Development of a Graphical User Interface to Visualize Upper-Air Meteorological Data (U), WSRC-TR-97-0213.

Manual on Codes, International Codes, Volume 1.1. Part A-Alphanumeric Codes, WMO-No. 306 (1995): World Meteorological Organization, Secretariat of the World Meteorological Organization, Geneva, Switzerland.

IDL User's Guide, Interactive Data Language, Version 4 (March 1995): Research System Inc., Boulder CO (USA).

Lutgens F. K., and E. J. Tarbuck (1989): The Atmosphere: An Introduction to Meteorology, Fourth Edition. Prentice Hall, Englewood Cliffs, NJ (USA), pp. 439444.

METAR "Aviation Routine Weather Report", Technical and Training Aids (1996): U.S. Department of Commerce, National Oceanic and Atmospheric Administration, Silver Spring, MD (USA).

Pielke R. A., W. R. Cotton, R. L. Walko, C. J. Tremback, W. A. Lyons, L. D. Grasso, M. E. Nicholls, M. D. Moran, D. A. Wesley, T. J. Lee, and J. H. Copeland, 1992: A comprehensive meteorological modeling system--RAMS. Meteor. Atmos. Phys., 49, 69-91. 


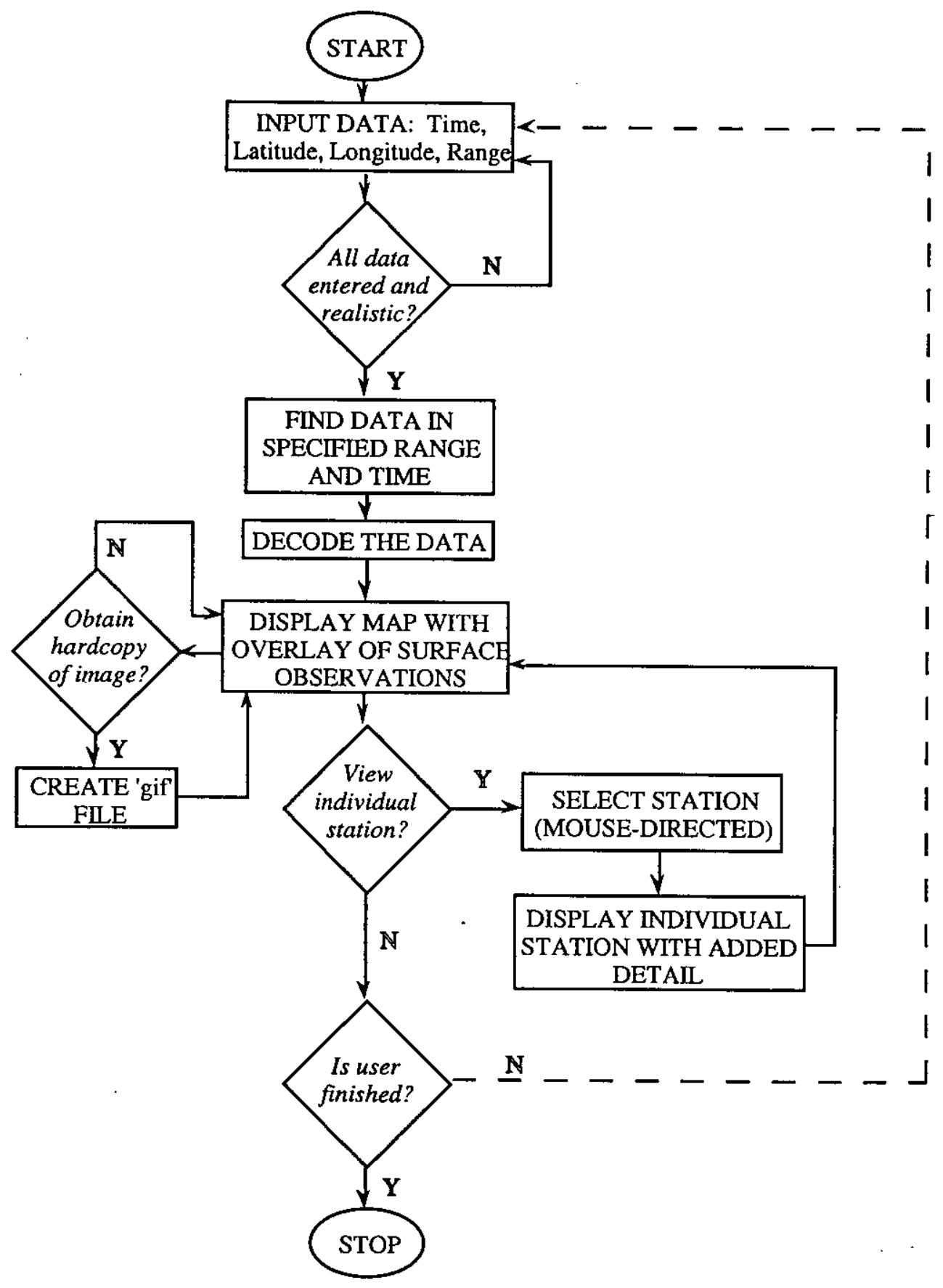

Figure 1: Flow diagram of the surface observation graphical user interface program. 


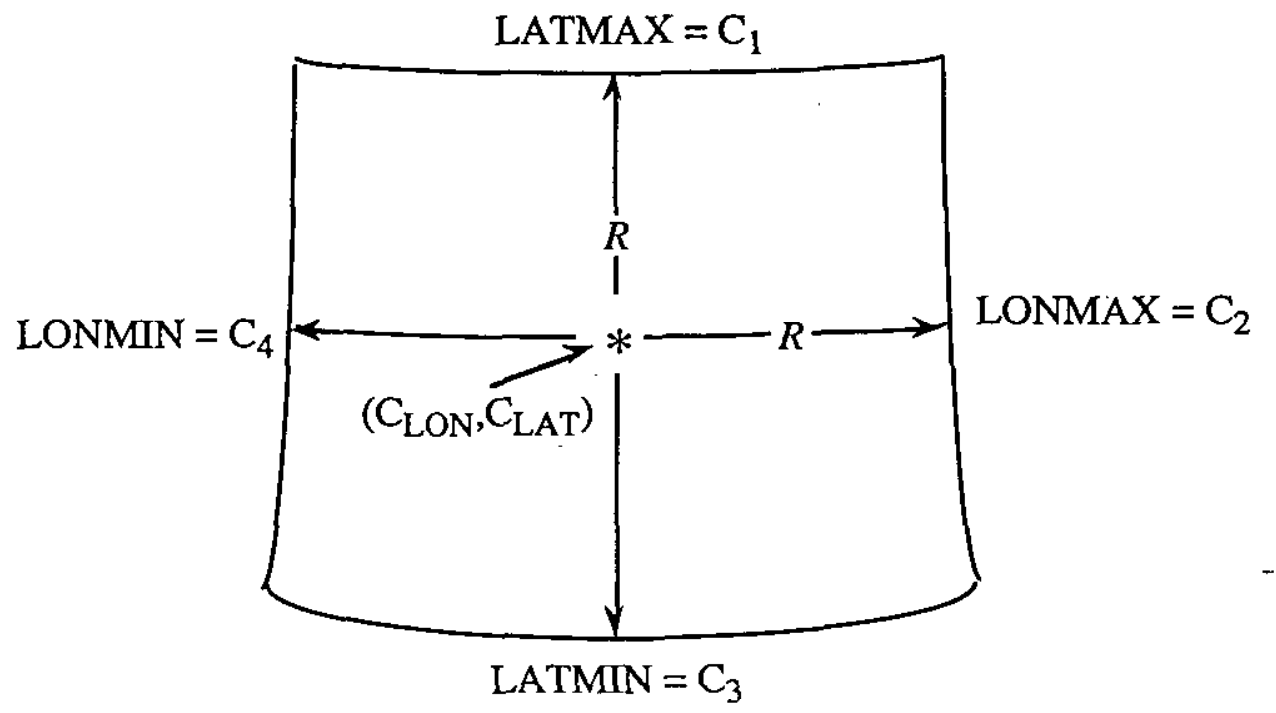

Figure 2: Determination of the area ('box') in which surface data is selected based on user input of center latitude (CLAT), center longitude (CLON), and range $(R)$. 
(a) METAR Stations

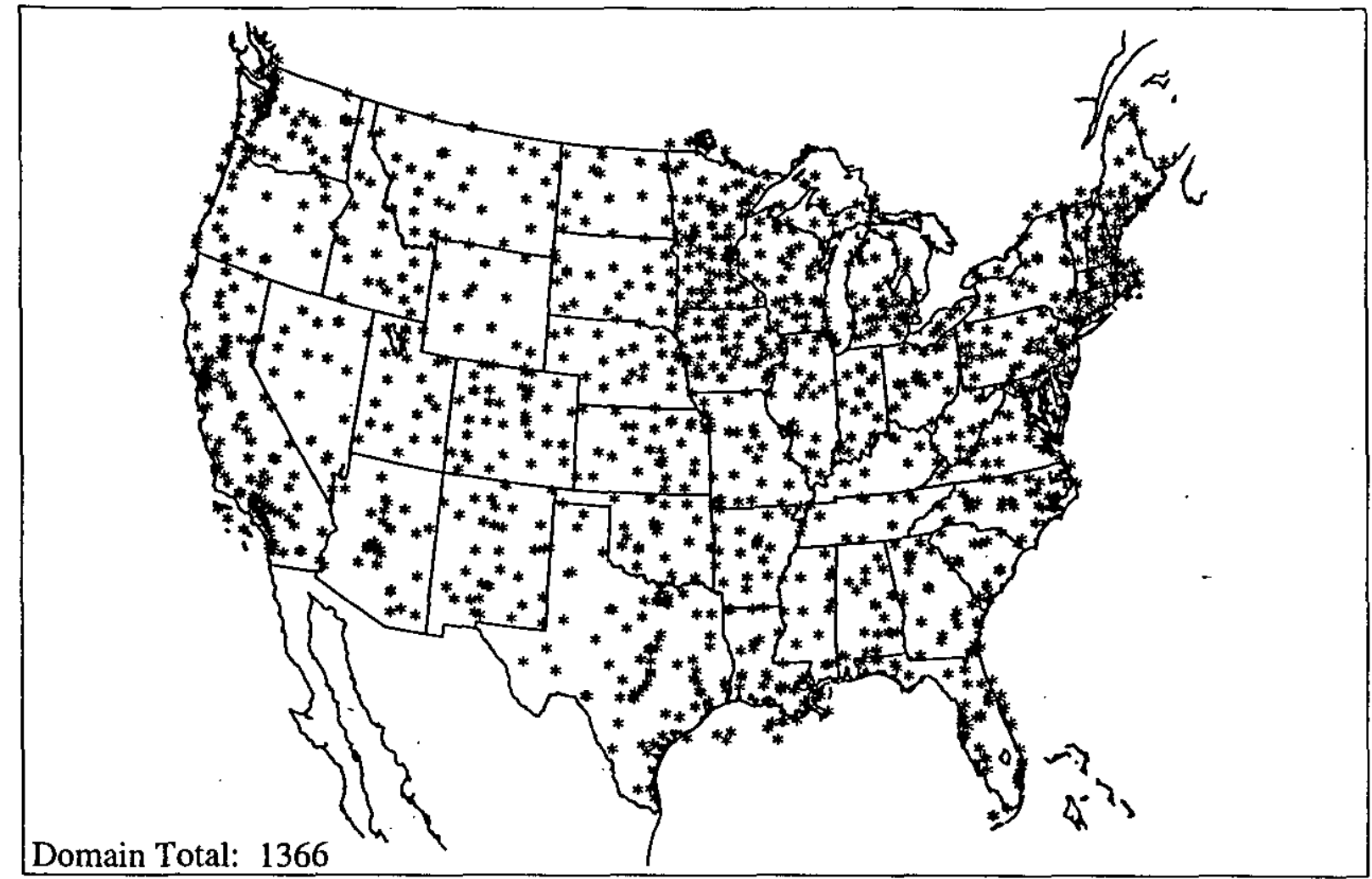

(b) WMO Synoptic Stations

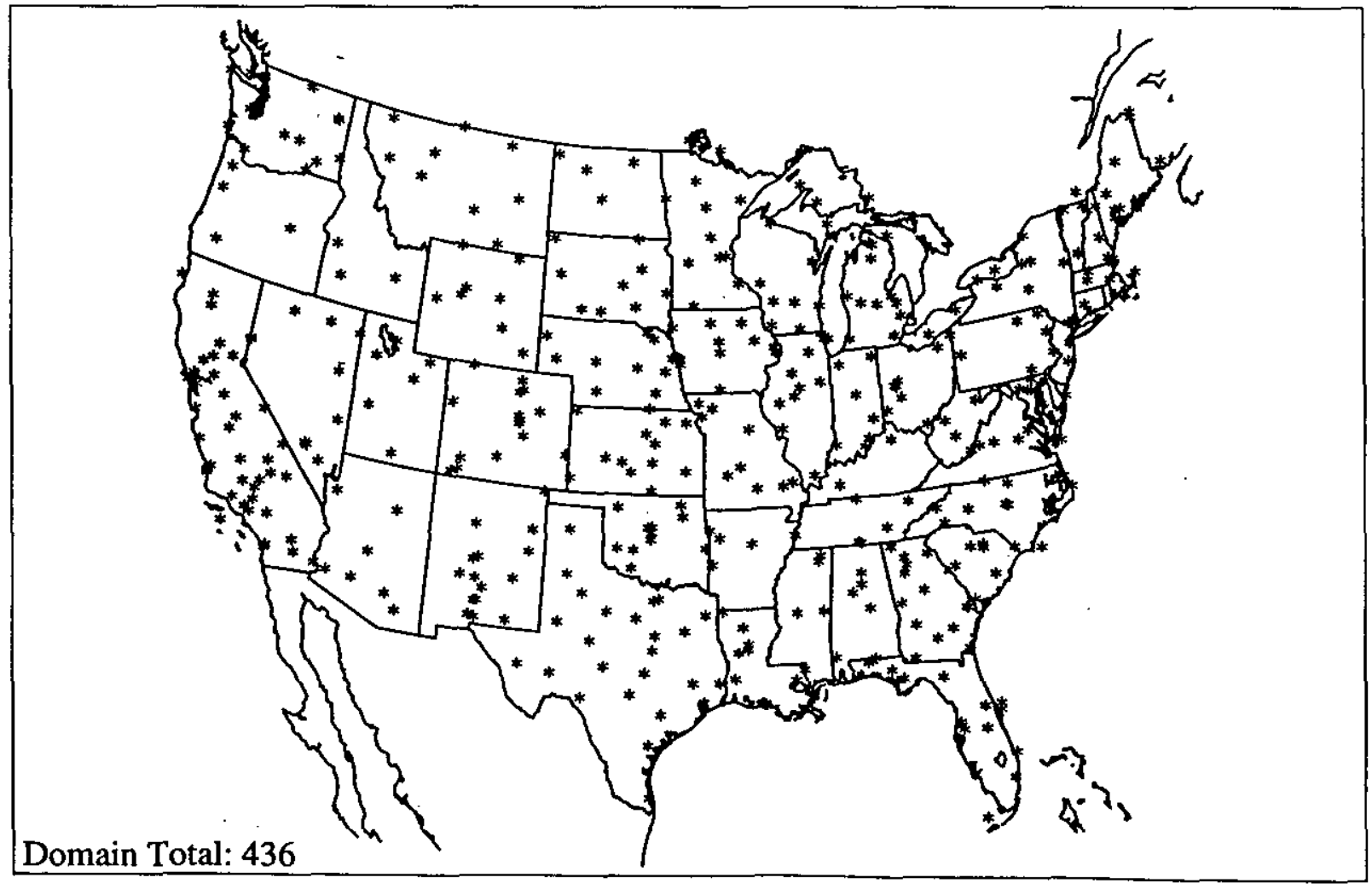




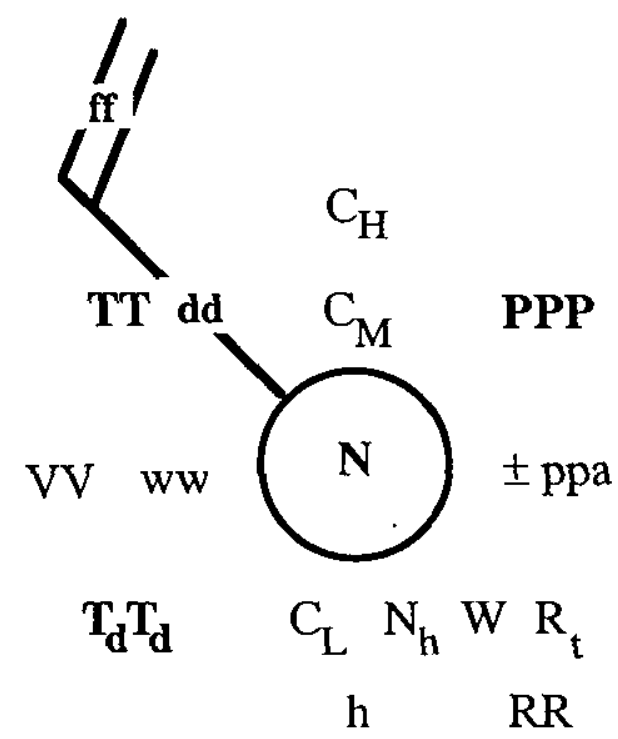

KEY to symbols: ff . Wind speed $\left(\mathrm{m} \mathrm{s}^{-1}\right)$

dd True direction FROM which wind is blowing

TT Temperature $\left({ }^{\circ} \mathrm{C}\right)$

$\mathrm{T}_{\mathrm{d}} \mathrm{T}_{\mathrm{d}} \quad$ Dew-point temperature $\left({ }^{\circ} \mathrm{C}\right)$

PPP Barometric pressure at mean sea level $(\mathrm{mb})$

N Total sky coverage (hollow $\Rightarrow$ clear, filled $\Rightarrow$ overcast)

VV Visibility $(\mathrm{km})$

ww Present weather

$\mathrm{C}_{\mathrm{H}} \quad$ High clouds (refers to altitude)

$\mathrm{C}_{\mathrm{M}} \quad$ Middle clouds

$\mathrm{C}_{\mathrm{L}} \quad$ Low clouds

$\mathrm{N}_{\mathrm{h}} \quad$ Fraction of sky covered by low or middle clouds

W Past weather

pp Pressure change $(\mathrm{mb})$ in past 3 hours

a Pressure tendency

$\mathrm{RR} \quad$ Amount of precipitation (mm)

$\mathrm{R}_{\mathrm{t}} \quad$ Time over which precipitation measurement was made (hr)

$h \quad$ Height (m) of the base of the lowest clouds

Figure 4: Symbolic station model and the meaning of associated letters. Further details may be found in Lutgens and Tarbuck, 1989. The values in bold lettering indicate items shown on the large map of the surface GUI. The units used in this application are shown in parantheses. 


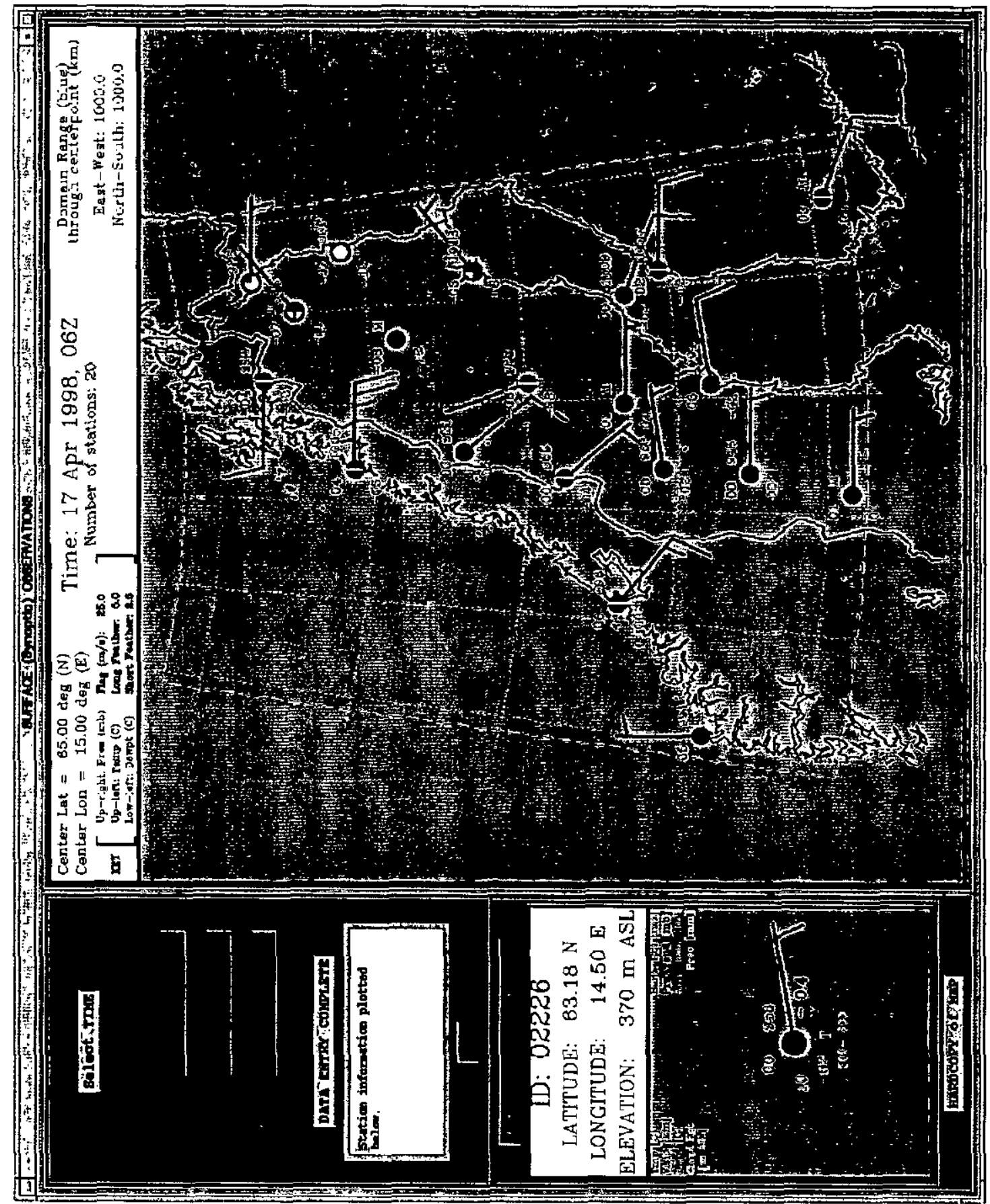

Figure 5: Screen image of the graphical user interface for a user-selected time (17 April 1998, 06Z) and location $\left(\mathrm{C}_{\mathrm{LAT}}=65^{\circ} \mathrm{N}, \mathrm{C}_{\mathrm{LON}}=15^{\circ} \mathrm{E}, R=1000 \mathrm{~km}\right.$ ) in northern Europe. 


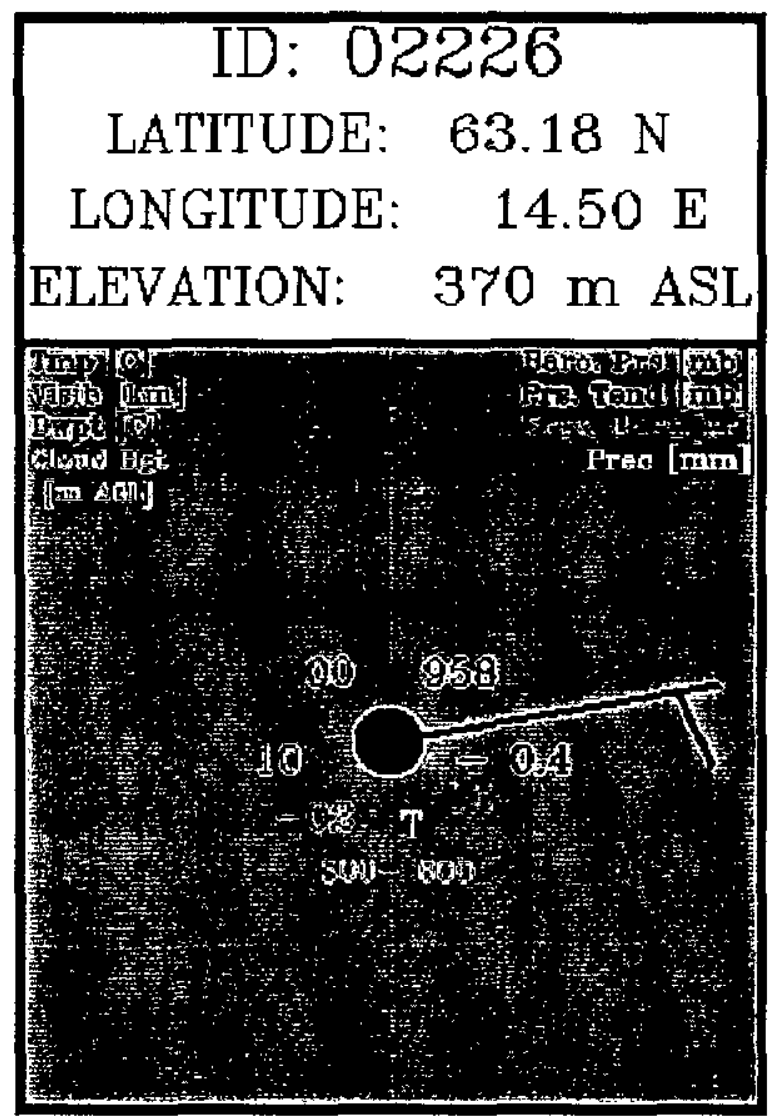

Figure 6: Screen image of an individual station report taken from Fig. 5. This station is located in Ostersund, Sweden. 


\section{APPENDIX}

This is the form of text output from the GUI which contains information on the number of stations reporting within the user-selected region, along with the station $\mathrm{ID}$, location, winds, temperature, dewpoint temperature, and pressure of each. Any meteorological value containing a value of -999.0 is missing or erroneously reported. Wind barbs are not shown on the images of the GUI in this case, while other values are denoted as missing ("M"). This is an example using the WMO synoptic surface bulletins.

\begin{tabular}{|c|c|c|c|c|c|c|c|c|}
\hline \multicolumn{9}{|c|}{20} \\
\hline ID & Lon & Lat & Elev & $\mathrm{D}[\operatorname{deg}]$ & $\mathrm{S}[\mathrm{m} / \mathrm{s}]$ & $\mathrm{T}\left[{ }^{\circ} \mathrm{C}\right]$ & $\operatorname{Dew}\left[{ }^{\circ} \mathrm{C}\right]$ & $\operatorname{Prs}[\mathrm{mb}]$ \\
\hline 01152 & 14.367 & 67.250 & 20.00 & 90. & 13.38 & 4.4 & -4.7 & 1005.0 \\
\hline 01205 & 5.267 & 62.333 & 41.00 & 360 . & 4.63 & 5.3 & 4.4 & 991.0 \\
\hline 01241 & 9.600 & 63.700 & 7.00 & 130. & 8.24 & 6.4 & -0.4 & 996.1 \\
\hline 02020 & 18.167 & 68.417 & 517.00 & 270 . & 6.18 & -3.6 & -10.0 & 948.8 \\
\hline 02043 & 21.067 & 67.933 & 341.00 & 50 & 1.54 & -7.0 & -11.4 & 974.5 \\
\hline 02080 & 22.500 & 68.450 & 327.00 & 90. & 2.57 & -7.4 & -14.0 & 976.2 \\
\hline 02096 & 23.400 & 67.217 & 168.00 & -999. & -999.00 & -7.0 & -12.8 & 997.3 \\
\hline 02104 & 15.100 & 65.817 & 473.00 & 140 & 6.69 & 0.4 & -4.6 & 950.9 \\
\hline 02128 & 17.700 & 64.967 & 283.00 & 340 . & 1.03 & -6.0 & -7.5 & 976.4 \\
\hline 02142 & 19.650 & 66.633 & 264.00 & -999 . & -999.00 & -8.1 & -11.5 & -999.0 \\
\hline 02186 & 22.133 & 65.550 & 34.00 & 50 & 2.57 & -3.1 & -7.8 & 1013.1 \\
\hline 02222 & 14.133 & 64.500 & 330.00 & 140. & 4.63 & 0.4 & -3.6 & 965.1 \\
\hline 02226 & 14.500 & 63.183 & 370.00 & 80. & 4.12 & 0.4 & -1.8 & 957.5 \\
\hline 02244 & 16.867 & 63.700 & 210.00 & 90. & 2.57 & 1.0 & -4.4 & -999.0 \\
\hline 02288 & 20.767 & 63.600 & 6.00 & 110. & 7.21 & 0.4 & -4.4 & 1008.7 \\
\hline 02324 & 14.367 & 62.033 & 360.00 & 90. & 4.63 & 0.0 & -0.4 & 948.0 \\
\hline 02366 & 17.450 & 62.533 & 10.00 & 80. & 6.69 & 2.9 & -1.6 & 1003.8 \\
\hline 02410 & 13.717 & 60.683 & 308.00 & 90. & 2.57 & 1.0 & 0.9 & -999.0 \\
\hline 02912 & 21.583 & 63.100 & 14.00 & 90. & 5.66 & 2.1 & -12.1 & 1006.6 \\
\hline 02963 & 23.500 & 60.817 & 103.00 & 110. & 7.72 & 3.2 & -3.5 & -999.0 \\
\hline
\end{tabular}




\section{DEVELOPMENT OF A GRAPHICAL USER INTERFACE TO VISUALIZE SURFACE OBSERVATIONS (U)}

\section{DISTRIBUTION}

P. Deason, 773-A

A. L. Boni, 773-A

R. P. Addis, 773-A

W. W. Bowman, 735-A

K. F. Chen, 773-A

A. J. Garrett, 773-A

D. P. Griggs, 773-A

C. H. Heavner, $773-42 \mathrm{~A}$

C. H. Hunter, 773-A

R. J. Kurzeja, 773-A

M. J. Parker, 735-7-A

B. L. O'Steen, 773-A

G. L. Snyder, 773-A

A. H. Weber, 773-A

R. L. Buckley, 773-A

SRTC Records(4), 773-52A

ATG Records(5), 773-A 